American Journal of Agricultural and Biological Sciences 4 (4): 305-310, 2009

ISSN 1557-4989

(C) 2009 Science Publications

\title{
The Determination of Optimal Crop Pattern with Aim of Reduction in Hazards of Environmental
}

\author{
Mahmoud Daneshvar Kakhki, Nasser Sahnoushi and F. Salehi Reza Abadi \\ Department of Agricultural Economics, \\ Ferdowsi University of Mashhad, P.O. Box 91775-1163, Mashhad, Iran
}

\begin{abstract}
Problem statement: The purpose of the study was to find the optimal cropping pattern, in Taybad, which maximizes the net return per water cubic meter and per fertilizer kilogram. Approach: A linear programming model and a fuzzy multi-objective fractional programming model were applied and then these models were compared. Results: Result of study showed ratio of net return into consumption of inputs and Ratio of consumption of inputs into area under cultivation are improved with applying of FMOLFP. Conclusion: FMOLFP models can be used as an effective tool for optimal cropping pattern when in addition to economical goals, environmental goals are noticed. Managers and decision makers can apply these models for optimization of ratio of objectives.
\end{abstract}

Key words: Cropping pattern, fuzzy multi-objective fractional programming, linear programming, net return, water, fertilizer

\section{INTRODUCTION}

Today growing population of world has increased the need for agricultural products and consequently increased the pressure on based resources that is required for those products.

With respect to the climatic conditions of the Iran, groundwater is the major source of crop irrigation. Especially in dry and semidry areas, agriculture depends largely on groundwater withdrawals. Overdraft of groundwater leads to decline in groundwater level. While the low input sustainable agriculture systems as part of sustainable agriculture, seek to optimize the management and use of internal production inputs (i.e., on-farm resource) and to minimize the use of production inputs (i.e., off farm resources), such as purchased fertilizers and pesticides, wherever feasible and practicable, to lower production cost, to avoid pollution of surface and groundwater, to reduce pesticide residues in food, to reduce a farmer's overall risk and to increase both short-and long-term farm profitability ${ }^{[6]}$.

Mathematical programming is a tool for management problem. Linear Programming (LP) is the oldest technique used in the farm management studies. Fractional programming is the most ordinary kind of mathematical programming with ratio of objectives ${ }^{[9]}$. In some managerial problems, maximization of two objectives that are in the form of comparative, can be inconsistent or in a programming problem optimizing the several fractional objectives are considerable simultaneously. These are example of fractional multiobjective programming. There are many published studies which used mathematical programming methodology to determine optimal crop pattern. Singh et al. ${ }^{[11]}$ used a linear programming model to reach optimized crop pattern at various available water levels. Haouari and Azaiez ${ }^{[3]}$ represented a mathematical programming for determining crop pattern in dry lands under scarce of water resources. Itoh et al. ${ }^{[4]}$ proposed a model of crop planning with uncertain (stochastic) values which may support decision making of agricultural farms. Biswas and Pal ${ }^{[1]}$ presented how fuzzy goal programming can be efficiently used for modeling and solving land-use planning problems in agricultural systems for optimal production of several seasonal crops in a planning year. Sharma et al ${ }^{[9]}$ introduced a fuzzy goal programming for allocation of agricultural land.

This study follows the optimization of crop pattern and allocation of scarce resources such as water in Taybad. Taybad located in state of Khorasn Razavi in Iran. This study tries to in addition to maximization of profit, minimizes the consumption of water and fertilizer and attends economical goals simultaneous with environmental goals. In this study was applied a Linear Programming (LP) model and a Fuzzy MultiObjective Linear Fractional Programming (FMOLFP)

Corresponding Author: Mahmoud Daneshvar Kakhki, Department of Agricultural Economics, Ferdowsi University of Mashhad, P.O. Box 91775-1163, Mashhad, Iran Tel: 00989155013517 Fax : 0098-5118795613 
model for determination of optimal cropping pattern in Taybad then these models were compared.

\section{MATERIALS AND METHODS}

FMOLFP formulation: In general, a multi-objective linear fractional programming problem can be formulated as follows:

$$
\text { subject to } X \in S=\left\{X \in R^{n} \mid A X\left(\begin{array}{l}
\leq \\
= \\
\geq
\end{array}\right) b, X \geq 0, b \in R^{m}\right\}
$$

where, $c_{k}, d_{k} \in R^{n}, \alpha_{k}, \beta_{k} \in R$ and $d_{k} X+\beta_{k}>\forall X \in S$.

Now, if an imprecise aspiration level is introduced to each of the objectives then, these fuzzy objectives are termed as fuzzy goals.

Let $g_{k}$ be the aspiration level of the kth objective $F_{k}(X)$. Then the fuzzy goals may appear in one of the forms:

- $\mathrm{F}_{\mathrm{k}}(\mathrm{X}) \gtrsim \mathrm{g}_{\mathrm{k}}$ (for maximizing $\mathrm{F}_{\mathrm{k}}(\mathrm{X})$ )

- $\mathrm{F}_{\mathrm{k}}(\mathrm{X}) \lesssim \mathrm{g}_{\mathrm{k}}\left(\right.$ for minimizing $\mathrm{F}_{\mathrm{k}}(\mathrm{X})$ )

and where $\gtrsim$ and $\lesssim$ indicate the fuzziness of $\geq$ and $\leq$ restrictions, respectively, in the sense of Zimmermann $^{[13]}$.

Hence, the fuzzy linear fractional goal programming can be presented as follows:

$\mathrm{F}_{\mathrm{k}}(\mathrm{X}) \lesssim \mathrm{g}_{\mathrm{k}}, \mathrm{k}=\mathrm{k}_{1}+1, \ldots, \mathrm{K}$

In a fuzzy decision-making situation, the fuzzy goals are characterized by their membership functions by defining the lower or upper tolerance limit and that depends on the fuzzy restriction given to a fuzzy goal of the problem.

Let $l_{k}$ and $u_{k}$ be the lower and upper tolerance limit for the kth fuzzy goal. Then the membership function, say $\mu_{\mathrm{k}}(\mathrm{X})$, for the fuzzy goal $\mathrm{F}_{\mathrm{k}}(\mathrm{X})$ can be characterized as follows ${ }^{[12]}$ :

For the $\gtrsim$ type of restriction, $\mu_{\mathrm{k}}(\mathrm{X})$ takes the form:

$$
\mu_{k}(X)=\left\{\begin{array}{cl}
1 & \text { if } F_{k}(X) \geq g_{k} \\
\frac{F_{k}(X)-I_{k}}{g_{k}-I_{k}} & \text { if } l_{k} \leq F_{k}(X) \leq g_{k} \\
0 & \text { if } F_{k}(X) \leq 1_{k}
\end{array}\right.
$$

Again for $\lesssim$ type of restriction, $\mu_{\mathrm{k}}(\mathrm{X})$ becomes:

$$
\mu_{k}(X)=\left\{\begin{array}{cl}
1 & \text { if } F_{k}(X) \leq g_{k} \\
\frac{u_{k}-F_{k}(X)}{u_{k}-g_{k}} & \text { if } g_{k} \leq F_{k}(X) \leq u_{k} \\
0 & \text { if } F_{k}(X) \geq u_{k}
\end{array}\right.
$$

A Goal Programming (GP) procedure for FMOLFP was applied. This procedure presented by $\mathrm{Pal}$ et al. ${ }^{[8]}$. We represented this method in the following.

Goal programming formulation: In a fuzzy decision environment, the achievement of the objective goals to their aspired levels to the extent possible is actually represented by the possible achievement of their respective membership values to the highest degree. Regarding this aspect of fuzzy programming problems, a GP approach seems to be most appropriate for the problem considered in this study.

In fuzzy programming approaches, the highest degree of membership function is 1 . So, as in Mohamed $^{[7]}$, for the defined membership functions in (3) and (4), the flexible membership goals with the aspired level 1 can be presented as:

$$
\frac{F_{k}(X)-l_{k}}{g_{k}-l_{k}}+d_{k}^{-}-d_{k}^{+}=1
$$

$\frac{\mathrm{u}_{\mathrm{k}}-\mathrm{F}_{\mathrm{k}}(\mathrm{X})}{\mathrm{u}_{\mathrm{k}}-\mathrm{g}_{\mathrm{k}}}+\mathrm{d}_{\mathrm{k}}^{-}-\mathrm{d}_{\mathrm{k}}^{+}=1$

where, $\mathrm{d}_{\mathrm{k}}^{-}(\geq 0)$ and $\mathrm{d}_{\mathrm{k}}^{+}(\geq 0)$ represent the under- and over-deviations, respectively, from the aspired levels and $\mathrm{d}_{\mathrm{k}}^{-} \cdot \mathrm{d}_{\mathrm{k}}^{+}=1$.

In conventional GP, the under- and/or overdeviational variables are included in the achievement function for minimizing them and that depend upon the type of the objective functions to be optimized.

In this approach, only the under-deviational variable $\mathrm{d}_{\mathrm{k}}^{-}$is required to be minimized to achieve the aspired levels of the fuzzy goals. It may be noted that any over-deviation from a fuzzy goal indicates the full achievement of the membership value ${ }^{[2,8]}$.

The membership goals in (5) and (6) are nonlinear, which may create computational difficulties in the solution process. In order to solve the problem, a linearization procedure is presented in the following.

Linearization of membership goals: The kth membership goal in (5) can be presented as follows: 
$\mathrm{L}_{\mathrm{k}} \mathrm{F}_{\mathrm{k}}(\mathrm{X})-\mathrm{L}_{\mathrm{k}} \mathrm{l}_{\mathrm{k}}+\mathrm{d}_{\mathrm{k}}^{-}-\mathrm{d}_{\mathrm{k}}^{+}=1$

where, $\mathrm{L}_{\mathrm{k}}=\frac{1}{\mathrm{~g}_{\mathrm{k}}-\mathrm{l}_{\mathrm{k}}}$.

Introducing the expression (1), (7) can be presented as the following procedures:

$$
\mathrm{L}_{\mathrm{k}}\left(\mathrm{c}_{\mathrm{k}} \mathrm{X}+\alpha_{\mathrm{k}}\right)+\mathrm{d}_{\mathrm{k}}^{-}\left(\mathrm{d}_{\mathrm{k}} \mathrm{X}+\beta_{\mathrm{k}}\right)-\mathrm{d}_{\mathrm{k}}^{+}\left(\mathrm{d}_{\mathrm{k}} \mathrm{X}+\beta_{\mathrm{k}}\right)=\mathrm{L}_{\mathrm{k}}^{\prime}\left(\mathrm{d}_{\mathrm{k}} \mathrm{X}+\beta_{\mathrm{k}}\right)
$$

Where:

or

$$
\mathrm{L}_{\mathrm{k}}^{\prime}=1+\mathrm{L}_{\mathrm{k}} \mathrm{l}_{\mathrm{k}}
$$

$$
\mathrm{C}_{\mathrm{k}} \mathrm{X}+\mathrm{d}_{\mathrm{k}}^{-}\left(\mathrm{d}_{\mathrm{k}} \mathrm{X}+\beta_{\mathrm{k}}\right)-\mathrm{d}_{\mathrm{k}}^{+}\left(\mathrm{d}_{\mathrm{k}} \mathrm{X}+\beta_{\mathrm{k}}\right)=\mathrm{G}_{\mathrm{k}}
$$

Where:

$\mathrm{C}_{\mathrm{k}}=\mathrm{L}_{\mathrm{k}} \mathrm{c}_{\mathrm{k}}-\mathrm{L}_{\mathrm{k}}^{\prime} \mathrm{d}_{\mathrm{k}}, \mathrm{G}_{\mathrm{k}}=\mathrm{L}_{\mathrm{k}}^{\prime} \beta_{\mathrm{k}}-\mathrm{L}_{\mathrm{k}} \alpha_{\mathrm{k}}$

Goal expressions for the membership goal in (6) can also be obtained similarly.

The goal expression in (8) can be linearized as follows ${ }^{[5]}$ :

Letting $D_{k}^{-}=d_{k}^{-}\left(d_{k} X+\beta_{k}\right)$ and $D_{k}^{+}=d_{k}^{+}\left(d_{k} X+\beta_{k}\right)$, the linear form of the expression in (8) is obtained as:

$\mathrm{C}_{\mathrm{k}} \mathrm{X}+\mathrm{D}_{\mathrm{k}}^{-}-\mathrm{D}_{\mathrm{k}}^{+}=\mathrm{G}_{\mathrm{k}}$

With $D_{k}^{-}-D_{k}^{+} \geq 0$ and $D_{k}^{-} \cdot D_{k}^{+}=0$ since $D_{k}^{-}, D_{k}^{+} \geq 0$ and $\mathrm{d}_{\mathrm{k}} \mathrm{X}+\beta_{\mathrm{k}}>0$.

Now, in making decision, minimization of $\mathrm{d}_{\mathrm{k}}^{-}$ means minimization of $D_{k}^{-} /\left(d_{k} X+\beta_{k}\right)$, which is also a non-linear one.

Clearly, when a membership goal is fully achieved, $\mathrm{d}_{\mathrm{k}}^{-}=0($ i.e.,$\mu=1)$ and when it is zero achieved $\mathrm{d}_{\mathrm{k}}^{-}=1(\mathrm{i} . \mathrm{e} ., \mu=0)$ are found in the solution. This leads to the following constraints to the model of the problem:

$\frac{D_{k}^{-}}{d_{k} X+\beta_{k}} \leq 1$

Equation 10 can be expressed as the other form below:

$$
-\mathrm{d}_{\mathrm{k}} \mathrm{X}+\mathrm{D}_{\mathrm{k}}^{-} \leq \beta_{\mathrm{k}}
$$

Here, on the basis of the previous discussion, it may be pointed out that any such constraint corresponding to $\mathrm{d}_{\mathrm{k}}^{+}$does not arise in the model formulation.

Now, if the most widely used and simplest version of GP (i.e., minsum GP) is introduced to formulate the model of the problem under consideration, then the GP model formulation becomes:

Find $\mathrm{X}$ so as to:

$$
\begin{array}{ll}
\text { Minimize } & \mathrm{F}=\sum_{\mathrm{k}=1}^{\mathrm{K}} \mathrm{W}_{\mathrm{k}}^{-} \mathrm{D}_{\mathrm{k}}^{-} \\
\text {and satisfy } & \mathrm{C}_{\mathrm{k}} \mathrm{X}+\mathrm{D}_{\mathrm{k}}^{-}-\mathrm{D}_{\mathrm{k}}^{+}=\mathrm{G}_{\mathrm{k}} \\
\text { subject to } & \mathrm{AX}\left(\begin{array}{l}
\leq \\
= \\
\geq
\end{array}\right) \mathrm{b} \\
\text { and } & \\
& -\mathrm{d}_{\mathrm{k}} \mathrm{X}+\mathrm{D}_{\mathrm{k}}^{-} \leq \beta_{\mathrm{k}} \\
& \mathrm{X} \geq 0 \\
& \mathrm{D}_{\mathrm{k}}^{-}, \mathrm{D}_{\mathrm{k}}^{+} \geq 0, \quad \mathrm{k}=1,2, \ldots, \mathrm{K}
\end{array}
$$

where, $\mathrm{Z}$ represents the fuzzy achievement function consisting of the weighted under-deviational variables, where the numerical weights $\mathrm{W}_{\mathrm{k}}^{-}(\geq 0), \mathrm{k}=1,2, \ldots, \mathrm{K}$ represent the relative importance of achieving the aspired levels of the respective fuzzy goals subject to the constraints set in the decision situation. $\mathrm{W}_{\mathrm{k}}^{-}$values are determined as ${ }^{[7]}$ :

$\mathrm{W}_{\mathrm{k}}^{-}= \begin{cases}\frac{1}{\mathrm{~g}_{\mathrm{k}}-\mathrm{l}_{\mathrm{k}}} & \text { for the defined } \mu_{\mathrm{k}} \text { in (3) } \\ \frac{1}{\mathrm{u}_{\mathrm{k}}-\mathrm{g}_{\mathrm{k}}} & \text { for the defined } \mu_{\mathrm{k}} \text { in (4) }\end{cases}$

The minsum GP method ${ }^{[13]}$ can then be used to solve the problem in (11).

\section{Case study:}

LP model: The model used was as follows:

- The objective function:

$$
\text { Minimize } F=\sum_{i=1}^{n} C_{1} X_{1}
$$

Where:

$\mathrm{Z}=$ The total net return from all the crops (Rs.)

$\mathrm{n}=$ The number of crops

$\mathrm{C}_{1}=$ The net return from ith crop (Rs. $\left.\mathrm{ha}^{-1}\right)$

$\mathrm{X}_{1}=$ The crop area under ith crop (ha)

The objective function was subject to linearity and non-negativity constraints. 


\section{The linearity constrains:}

- Water availability constraints:

$$
\begin{aligned}
& \sum_{\mathrm{i}=1}^{\mathrm{n}} \mathrm{W}_{\mathrm{spi}} \mathrm{X}_{\mathrm{i}} \leq \mathrm{W}_{\mathrm{Sp}} \\
& \sum_{\mathrm{i}=1}^{\mathrm{n}} \mathrm{W}_{\mathrm{sui}} \mathrm{X}_{\mathrm{i}} \leq \mathrm{W}_{\mathrm{Su}} \\
& \sum_{\mathrm{i}=1}^{\mathrm{n}} \mathrm{W}_{\mathrm{fi}} \mathrm{X}_{\mathrm{i}} \leq \mathrm{W}_{\mathrm{f}} \\
& \sum_{\mathrm{i}=1}^{\mathrm{n}} \mathrm{W}_{\mathrm{wi}} \mathrm{X}_{\mathrm{i}} \leq \mathrm{W}_{\mathrm{w}}
\end{aligned}
$$

Where:

$\mathrm{W}_{\text {spi }}$

$\mathrm{W}_{\text {sui }}$

$\mathrm{W}_{\mathrm{fi}}$

$\mathrm{W}_{\mathrm{wi}}$

$\mathrm{W}_{\mathrm{sp}}, \mathrm{W}_{\mathrm{su}}, \mathrm{W}_{\mathrm{f}}$ and $\mathrm{W}_{\mathrm{w}}=$ The total water available in spring, summer, fall and winter, respectively

- Land area constraints:

$$
\sum_{i=1}^{n} X_{i} \leq A
$$

A is the area available for cultivation.

- Maximum and minimum area for each crop:

$$
\text { Min } \operatorname{area}_{\mathrm{i}} \leq \mathrm{X}_{\mathrm{i}} \leq \text { Max } \text { area }_{\mathrm{i}}
$$

- Fertilizer constraint:

$$
\sum_{\mathrm{i}=1}^{\mathrm{n}} \mathrm{F}_{\mathrm{i}} \mathrm{X}_{\mathrm{i}} \geq 0
$$

$\mathrm{F}_{\mathrm{i}}$ is the requirement fertilizer for ith crop $\left(\mathrm{kg} \mathrm{ha}^{-1}\right)$.

- Non-negativity constraints:

$$
\mathrm{X}_{\mathrm{i}} \geq 0
$$

FMOLFP model: The model used was as follows. The objective functions:
Maximize

$$
\mathrm{Z}_{1}=\frac{\sum_{\mathrm{i}=1}^{\mathrm{n}} \mathrm{C}_{\mathrm{i}} \mathrm{X}_{\mathrm{i}}}{\sum_{\mathrm{i}=1}^{\mathrm{n}} \mathrm{W}_{\mathrm{Sp} 1} \mathrm{X}_{1}}
$$

Maximize

$$
\mathrm{Z}_{2}=\frac{\sum_{\mathrm{i}=1}^{\mathrm{n}} \mathrm{C}_{\mathrm{i}} \mathrm{X}_{\mathrm{i}}}{\sum_{\mathrm{i}=1}^{\mathrm{n}} \mathrm{W}_{\mathrm{Sul}} \mathrm{X}_{1}}
$$

Maximize

$$
\mathrm{Z}_{3}=\frac{\sum_{\mathrm{i}=1}^{\mathrm{n}} \mathrm{C}_{\mathrm{i}} \mathrm{X}_{\mathrm{i}}}{\sum_{\mathrm{i}=1}^{\mathrm{n}} \mathrm{F}_{1} \mathrm{X}_{1}}
$$

Where:

$\sum_{\mathrm{i}=1}^{\mathrm{n}} \mathrm{C}_{\mathrm{i}} \mathrm{X}_{1}=$ The total net return from all of the crops

$\sum_{\mathrm{i}=1}^{\mathrm{n}} \mathrm{W}_{\mathrm{spi}} \mathrm{X}_{1}=$ The consumption of water in spring season

$\sum_{\mathrm{i}=1}^{\mathrm{n}} \mathrm{W}_{\text {Sui }} \mathrm{X}_{1}=$ The consumption of water in summer season

$\sum_{\mathrm{i}=1}^{\mathrm{n}} \mathrm{F}_{\mathrm{i}} \mathrm{X}_{1}=$ The consumption of fertilizer

The linearity constrains: The objective functions were subject to constraints. This model has the same constraints than Lp model.

\section{RESULTS}

Fuzzy aspiration levels and tolerance limits of the three objectives are reported in Table 1. With attention to Table 1, FMOLFP model was designed and then was solved.

Results of Lp and FMOLFP models are given in Table 2. Results show the area under wheat, beet sugar, cotton and melon are reduced in FMOLFP model and there were no change in cultivation area under barley and cumin.

Beet sugar had most reduction in area under cultivation. It is reduced about $53 \%$. It may be because of high water requirement of beet sugar especially in summer.

In FMOLFP model, net return is lower than net return in Lp about $21 \%$.

Table 1: Fuzzy aspiration levels and tolerance limits

\begin{tabular}{llll}
\hline & & Tolerance limits & \\
& Aspiration & ------------ \\
Objectives & levels & Lower & Upper \\
\hline$Z_{1}$ & 2610.48 & 2372.16 & $\infty+$ \\
$Z_{2}$ & 2636.58 & 2396.89 & $\infty+$ \\
$Z_{3}$ & 17291.12 & 15719.2 & $\infty+$ \\
\hline
\end{tabular}


Am. J. Agri. \& Biol. Sci., 4 (4): 305-310, 2009

Table 2: Results obtained for LP and FMOLFP

\begin{tabular}{lll}
\hline & LP & FMOLFP \\
\hline Wheat (ha) & 3552.2 & 2504.9 \\
Barly (ha) & 1555 & 1555 \\
Beet sugar (ha) & 484.5 & 226.9 \\
$\begin{array}{l}\text { Cotton (ha) } \\
\text { Melon (ha) }\end{array}$ & 2774.5 & 2058 \\
$\begin{array}{l}\text { Cumin (ha) } \\
\text { Net return (Rs.) }\end{array}$ & 3131.6 & 2381.9 \\
$\begin{array}{l}\text { Ratio of net return into consumption of } \\
\text { water in spring season }\left(\mathrm{Z}_{1}\right)\end{array}$ & $9.588 \mathrm{E}+10$ & 1062 \\
$\begin{array}{l}\text { Ratio of net return into consumption of } \\
\text { water in summer season }\left(\mathrm{Z}_{2}\right)\end{array}$ & $2373.5 \mathrm{E}+10$ \\
$\begin{array}{l}\text { Ratio of net return into consumption } \\
\text { of fertilizer (Z) }\end{array}$ & 2396.9 & 2636.6 \\
$\begin{array}{l}\text { Ratio of consumption of water in } \\
\text { spring season into area under cultivation }\end{array}$ & 15719.3 & 16192.1 \\
$\begin{array}{l}\text { Ratio of consumption of water in summer } \\
\text { season into area under cultivation }\end{array}$ & 3216.6 & 3197.6 \\
$\begin{array}{l}\text { Ratio of consumption of fertilizer into } \\
\text { area under cultivation }\end{array}$ & 485.6 & 2929.1 \\
\hline
\end{tabular}

\section{DISCUSSION}

This research intended to find the optimal cropping pattern, in Taybad, which maximizes the net return per water cubic meter and per fertilizer kilogram. A linear programming model and a fuzzy multi-objective fractional programming model were applied and then these models were compared. One of The important conclusion can be drawn from this study from the methodological point is that in FMOLFP model, net return is lower than net return in Lp. It is because of in Lp only maximization of net return was objective but in FMOLFP in addition to net return, environmental goals were entered into objective functions. In despite of reduction of net return, ratio of net return into consumption of inputs (i.e., water and fertilizer) was increased. On the other word net return per unit consumption of water/fertilizer was increased.

Ratio of consumption of water in spring season into area under cultivation improved in FMOLFP. It shows if farmers applied the cropping pattern resulted from FMOLFP, they will move toward sustainable agriculture.

\section{CONCLUSION}

FMOLFP models can be used as an effective tool for optimal cropping pattern when in addition to economical goals, environmental goals are noticed. Managers and decision makers can apply these models for optimization of ratio of objectives.

Result of study showed ratio of net return into consumption of inputs and Ratio of consumption of inputs into area under cultivation are improved with applying of FMOLFP.

\section{ACKNOWLEDGEMENT}

The researchers would like to thanks agricultural College of Ferdowsi University of Mashhad for financial support of this study. The main Project is registered under number B/181-1388.

\section{REFERENCES}

1. Biswas, A. and B.B. Pal, 2005. Application of fuzzy goal programming technique to land use planning in agricultural system. Int. J. Manage. Sci. Omega, 33: 391-398. $\quad$ DOI: 10.1016/j.omega.2004.07.003

2. Dyson, R.G., 1980. Maximin programming, fuzzy linear programming and multicriteria decision making. J. Operat. Res. Soc., 31: 263-267. http://www.jstor.org/stable/2581083

3. Haouari, M. and M. Azaiez, 2001. Optimal cropping patherns under water deficits. Eur. J. Operat. Res., 130: 133-146. DOI: 10.1016/S03772217(00)00028-X

4. Itoh, T., H. Ishii and T. Nanseki, 2003. A model of crop planning under uncertainty in agricultural management. Int. J. Prod. Econ., 81-82: 555-558. DOI: $10.1016 / \mathrm{S} 0925-5273(02) 00283-9$

5. Kornbluth, J.S.H. and R.E. Steur, 1981. Goal programming with linear fractional programming. Manage. Sci., 27: 1024-1039.

6. Low, A.R., 1993. The Low Input Sustainable Agriculture (LISA) prescription: A bitter pill or farm households in southern Africa. Project Appraisal, $\quad$ 8: 97-101. http://www.fao.org/agris/search/display.do?f=./199 6/v2209/GB9403769.xml;GB9403769

7. Mohamed, R.H., 1997.The relationship between goal programming and fuzzy programming. Fuzzy Set Syst., 89: 215-222. DOI: 10.1016/S01650114(96)00100-5

8. Pal, B.B., B.N. Moitra and U. Maulik, 2003. A goal programming procedure for fuzzy multiobjective linear fractional programming problem. Fuzzy Sets Syst., 139: 395-405. DOI: 10.1016/S0165-0114(02)00374-3

9. Romero, C. and T. Rehman, 1989. Multiple Criteria Analysis for Agricultural Decisions. Elsevier, Amsterdam.

10. Sharma, D.K., R.K. Jana and A. Gaur, 2007. Fuzzy goal programming for agricultural land allocation problems. Yugoslav J. Operat. Res., 17: 31-42. 
11. Singh, D.K., C.S. Jaiswal, K.S. Reddy, R.M. Singh and D.M. Bhandarkar, 2001. Optimal cropping pattern in a canal command area. Agric. Water Manage., 50: 1-8.

http://cat.inist.fr/?aModele $=$ afficheN\&cpsidt $=1029$ 523

12. Tiwari, R.N., S. Dharmar and J.R. Rao, 1987. Fuzzy goal programming-an additive model. Fuzzy Sets $\quad$ Sys., 24 27-34. http://portal.acm.org/citation.cfm?id=33305
13. Zadeh, L.A., 1965. Fuzzy sets. Inform Control, 8: 338-53.

14. Zimmermann, H.J., 1976. Description and optimization of fuzzy systems. Internat. J. Gen. Syst., 2: 209-215. 